\title{
Pockets of Inequality in the Distribution of U.S. Pharmacists' Wages and Salaries: A Gender Comparison
}

\author{
Manuel J. Carvajal ${ }^{a}$; loana Popovici ${ }^{a}$; Patrick C. Hardigan ${ }^{b}$ \\ ${ }^{a}$ Nova Southeastern University, College of Pharmacy, Department of Sociobehavioral and Administrative Pharmacy \\ ${ }^{b}$ Nova Southeastern University, College of Medicine
}

\begin{abstract}
Background: The literature contains conflicting arguments regarding inequalities in the distribution of U.S. pharmacists' wages and salaries and the existence of a gender earnings gap. Some authors argue that the dispersion is small compared to other professions and there is no gap; others report that after controlling for number of hours worked, human-capital stock, and job-related preferences, male pharmacists earn higher wages and salaries than female pharmacists. Objectives: Estimate the central tendency and spread of wages and salaries of pharmacists practicing in the U.S., compare earning levels of male and female pharmacists, and examine the pockets of inequality within each gender. Methods: The study used self-reported survey data collected from a random sample of licensed pharmacists practicing throughout the United States. The sample consisted of 375 men and 279 women. Means and standard deviations of wage-and-salary earnings for male and female pharmacists were estimated by age, number of hours worked, years of professional experience, marital status, type of pharmacy degree, main role as pharmacist, and type of practice site. The spread of wages and salaries within gender was analyzed using the Gini coefficient. Results: A total of 654 pharmacists provided answers to all relevant questions in the questionnaire (28.9\% response rate). Wages and salaries of male pharmacists exceeded those of female pharmacists, but the gap was restricted to practitioners with selected characteristics-older, married, with more experience, whose primary role was dispensing medications, and practicing in a hospital setting. The greatest wage-and-salary inequalities were observed among older pharmacists, with more years of professional experience, and whose primary role was dispensing medications. Different gender-specific pockets of inequality were identified in all variables studied and all categories within these variables. Conclusion: The seemingly smooth gender-specific distribution of earnings in the pharmacy profession might be the result of opposing trends by different groups of practitioners that cancel each other when analyzed aggregately. By estimating the wages and salaries for selected categories of pharmacists and examining the pockets of inequality within each gender, this study shed light into recent labor market developments and will hopefully stimulate further research into the dynamics of the pharmacist workforce.
\end{abstract}

Keywords: gender disparities, income distribution, pharmacist workforce, wages and salaries

\section{INTRODUCTION}

Probes into a distribution of earnings or any other asset have two components: location and dispersion. Location focuses on the central tendency of the distribution in search of its most representative or typical value, while dispersion examines how typical the most representative value really is; thus, dispersion depicts the extent of inequality present in the distribution. This article deals with the central tendency, inequality, and gender differences in the distribution of pharmacists' wages and salaries in the United States.

Pharmacy has been portrayed by Golden, Katz ${ }^{1}$ as the most egalitarian profession in the U.S., with the lowest earnings dispersion of the healthcare professions and a relatively low gender earnings gap compared to the earnings of all college graduates. A reason for this kind of portrayal is that

Corresponding author: Manuel J. Carvajal, PhD Nova Southeastern University, College of Pharmacy Department of Sociobehavioral and Administrative Pharmacy, 3200 South University Drive, Fort Lauderdale, FL, USA 33328

Phone: 954-262-1322; Fax: 954-262-2278

Email:cmanuel@nova.edu

Email: cmanuel

http://z.umn.edu/INNOVATIONS remuneration in pharmacy is fairly linear with respect to the number of hours and weeks worked, in such a way that there are virtually no gains to having a practitioner work long hours vis-a-vis two practitioners, each working one-half of those hours; in other words, the amount of wages and salaries is determined almost entirely by the number of hours worked. According to this reasoning, the process is very similar for male and female practitioners; hence the alleged absence of a gender earnings gap.

In an empirical setting, Carvajal, Armayor, Deziel ${ }^{2}$ have reached somewhat different conclusions. Beyond the number of hours worked, wage-and-salary earnings of male and female pharmacists were influenced by different indicators such as opinion variables and professional role, and when responding to the same variables (e.g., holding a PharmD degree, work experience, and primary practice setting), the effect varied by gender. Furthermore, after controlling for the effect of the number of hours worked, human-capital stock, and job-related preferences, male pharmacists continued to earn higher wages and salaries than female pharmacists, which suggests the existence of a gender gap. The incongruence in the arguments by both sets of authors has framed the research conducted here. 
Traditionally most of the wage-and-salary inequality in the United States has been attributed to inter-occupational differences (i.e., education; skills; demand for services; and ability to maintain institutional mechanisms of social closure such as licensing, educational credentialing, and unionization). Recently, however, intra-occupational inequality, which measures wage-and-salary disparities among workers with the same observable characteristics of an occupation or trade, has grown at a faster rate than wage disparities among workers of different occupations ${ }^{3}$. (This conclusion was reached after an occupational structure analysis of data, measured at the threedigit level, from the Current Population Survey.) Since most of the education, skills, demand for services, and ability to maintain institutional mechanisms of social closure remain relatively constant within a profession, wage-and-salary disparities must occur because of differences in the number of hours worked, productivity, intra-occupational human-capital stock, job-related preferences, and/or institutional rigidities such as market bias or discrimination.

Several studies throughout the world have analyzed earnings inequality by gender in recent years. For example, Dobre, Ailenei, Mosora ${ }^{4}$ examined women's wage discrimination in Romania using the Dacum decomposition of the Gini index; Haag, Schockmel ${ }^{5}$ divided the Gini index into subgroups for studying gender inequalities in Luxembourg; Chibba ${ }^{6}$ attempted to pair economic inequality and mothers' index rank using a data base of thirteen countries; Dorius, Firebaugh ${ }^{7}$ researched globally gender inequalities in key indicators of welfare; and Larraz ${ }^{8}$ proposed a new breakdown of the Gini inequality ratio to compute differences in salaries between men and women in Spain. All these studies have analyzed national income distribution; none of them has focused on a single profession or trade.

In the United Sates, only one study has attempted to estimate inequalities in the distribution of wages and salaries in the pharmacist workforce ${ }^{9}$. Using five indicators of inequality (variance of natural logarithm, coefficient of variation, lower median share, 90-10 decile ratio, and Gini coefficient), the findings of Carvajal, Armayor ${ }^{9}$ lent credence to the Goldin, Katz ${ }^{1}$ egalitarian contention compared to other professions, although the extent of inequality within male pharmacists generally was observed to be greater than within female pharmacists. Compared to their female counterparts, male pharmacists exhibited a larger log earnings variance (0.282 vs. 0.189), a greater coefficient of variation ( 0.417 vs. 0.282 ), a similar lower median share (0.381 vs. 0.405$)$, a larger $90-10$ decile ratio (6.11 vs. 3.90), and a slightly higher Gini coefficient ( 0.186 vs. 0.145 ). Unfortunately, no gender comparisons were undertaken to determine the human-capital or job-related categories within each gender in which the greatest disparities in wages and salaries existed. This article was designed to correct such deficiency.

\section{OBJECTIVES}

Within the context of the ideas expressed in the introduction, this study sought to accomplish three purposes: 1 ) estimate the central tendency (e.g., earnings levels) and spread (e.g., inequality) of wages and salaries for selected categories of U.S. practitioners, 2) compare the earnings levels of male and female pharmacists, and 3) examine the pockets of inequality within each gender. The gender comparisons also were conducted for selected categories of practitioners.

\section{METHODS}

This study was based on self-reported data. Participants were asked to disclose their annual wage-and-salary earnings working as pharmacists. They also were asked information about gender, age, average number of hours worked per week, number of years of professional experience, marital status, type of pharmacy degree, main role working as pharmacists, and type of practice site. These variables have been identified as statistically significant determinants of pharmacists' wages and salaries in various studies ${ }^{2,10-12}$. For analytical purposes here, they were divided into various categories.

For the first variable, age, three groups were identified: under 40 years old, $40-54$ years old, and 55 years and older. Full-time pharmacists (35 or more hours of work per week) were differentiated from part-time pharmacists (under 35 hours per week). Three professional experience categories were designed: under 15 years, 15-29 years, and 30 or more years, and married participants were separated from participants who were not married (e.g., never married, separated, divorced, or widowed). Practitioners also were classified into those who held a PharmD degree and those who did not. Three categories were identified according to pharmacists' main role (clinical, dispensing, and other) and three types of practice site (retail, hospital, and other) were distinguished.

\section{Earnings Levels}

For all participants and for men and women separately, the means and standard deviations of wage-and-salary earnings were estimated, for the categories within each variable mentioned above as well as for the entire data set. Significant differences among categories within each variable were estimated using Duncan's multiple-range test, and significant differences between male and female pharmacists within each category were established using the $t$ statistic for comparing the means of two distributions with unequal variances and unequal numbers of observations. Both are commonly used statistical tests and each comparison was made independently of the others. The use of Duncan's multiple-range test reduced the probability of reaching the wrong conclusion when comparing multiple categories within a variable. Three levels of (two-tail test) significance were identified ( $p \leq 0.01, p \leq 0.05$, and $p \leq 0.10$ ) to denote the strength of the differences estimated in the empirical results. 


\section{Earnings Inequality}

The spread of wages and salaries was analyzed using the Gini coefficient, the most frequently used measure of inequality ${ }^{13-}$ 15. It is usually defined in terms of the Lorenz curve, which in this case relates in the sample cumulative percentages of wageand-salary earnings to cumulative percentages of pharmacists arranged in ascending order of earnings (see Figure 1). Cumulative pharmacist percentages appear in the horizontal axis and cumulative earnings percentages appear in the vertical axis. A diagonal 45 degree line connecting the $(0,0)$ and $(1,1)$ coordinates represents perfect equality, in such a way that $10 \%$ of pharmacists would earn $10 \%$ of wages and salaries, $20 \%$ of pharmacists would get $20 \%$ of the earnings, and so on. When there is inequality, the lowest-earning $10 \%$ of pharmacists receive less than $10 \%$ of total wages and salaries, and the Lorenz curve lies below the 45-degree line. More inequality pushes the Lorenz curve further down from the 45-degree line.

If the area between the 45 degree line and the Lorenz curve is called $A$ and the area below the Lorenz curve is called $B$, the value of the Gini coefficient is determined by the ratio of area $A$ divided by area $A+B$, that is, the triangle under the line. Since it is a percentage, its possible values range between zero and one. If earnings inequality rises, area $A$ would grow relatively to area $B$, and the value of the Gini coefficient would go up; conversely, a value of zero denotes perfect equality.

Throughout the years, the Gini coefficient has been estimated in different ways ${ }^{16-22}$. In this article, it was obtained using the methodology proposed by Moskowitz, Seshan, Riedel, Begg ${ }^{23}$ and later applied by Carvajal, Armayor ${ }^{9}$. Specifically,

$$
G C=1-\sum_{k=1}^{n}\left(X_{k}-X_{k-1}\right)\left(Y_{k}+Y_{k-1}\right)
$$

where

$\mathrm{X}_{\mathrm{k}} \quad$ is the cumulative percentage of pharmacists arranged in ascending order of wages and salaries earned by the kth fractile;

$Y_{k} \quad$ is the cumulative percentage of wages and salaries earned by the cumulative percentage of pharmacists of the kth fractile;

$\mathrm{k}=1, \ldots, \mathrm{n}$; and

$\mathrm{n} \quad$ is the number of fractiles identified in the data set.

In this paper, the Gini coefficient was calculated using each pharmacist in the data set rather than predetermined fractile intervals. In other words, each pharmacist constituted a fractile. Thus, the number of fractiles was large and the fractile intervals were minimized, which approximated a smooth function for the Lorenz curve. Since the Gini coefficient does not involve any statistical test, no levels of significance between the genders were established; however, differences in values of $40 \%$ and $25 \%$ were identified.

\section{Data}

The data for this study were obtained using Medical Marketing Services (MMS), a leading provider of pharmacists' lists in the U.S. The names in their depository are drawn from pharmacists registered with APhA, ASHP, AACP, and other organizations, and all fields within the profession are represented. Approximately $90 \%$ of the estimated 281,560 pharmacists practicing in $2012^{24}$ were included in the MMS data files.

A survey questionnaire*, previously validated and designed for this and other workforce studies, was mailed by the authors in March 2012 to a simple random sample of 2,400 pharmacists practicing throughout the United States selected by MMS, with a reminder sent two weeks later. The sample size was chosen according to Cochran's formula developed for categorical and other outcomes, with a $5 \%$ sampling error ${ }^{27}$. The research effort was supported solely by internal university funds, and institutional review board approval was obtained to conduct the probe.

\section{RESULTS}

Of the 2,400 questionnaires mailed to potential participants, 139 packets were returned undelivered for various reasons. A total of 654 pharmacists participated in the study by providing answers to all relevant questions for a $28.9 \%$ response rate. The number of observations and the response rate compared favorably with those reported by similar undertakings ${ }^{28-31}$. Of the respondents, 375 were male pharmacists (57.3\%) and 279 were female pharmacists $(42.7 \%)$.

\section{Earnings Levels Comparisons}

The means and standard deviations of wages and salaries reportedly earned by male and female pharmacists in the sample, as well as in selected categories within variables, are presented in Table 1 . When the observations for men and women were merged, no significant differences by age group, years-of-experience group, or marital status were detected. Pharmacists with a PharmD degree earned higher wages and salaries than pharmacists without a PharmD degree, and pharmacists who worked full time reported greater earnings than those who worked part time. Pharmacists whose primary role was dispensing medications earned lower wages and salaries than pharmacists whose primary role was clinical or other, and pharmacists in retail and hospital settings reported lower earnings than pharmacists in other settings but not significantly different levels between them.

\footnotetext{
*The questionnaire was initially tested with a group of 20 practitioners whose responses were not part of the data set; subsequently, it served as the basis of other empirical studies ${ }^{25,26}$.
} 
Overall male pharmacists earned $8.1 \%$ higher wages and salaries than their female counterparts, and the difference was statistically significant. But the gender gap was not ubiquitous. It was detected in practitioners 40 years of age or older, but not in younger practitioners; it was not detected within either fulltime or part-time practitioners; it was detected in practitioners with 15-29 years of experience, but not in those with fewer or more years; it was detected in married practitioners, but not in those who were not married; it was detected in practitioners both with and without a PharmD degree; it was detected in practitioners whose primary role was dispensing, but not in those whose primary role was clinical or other; and it was detected in pharmacists practicing in hospitals but not in those practicing in retail or other settings.

\section{Earnings Inequality Comparisons}

The estimated Gini coefficient values for male and female pharmacists in the sample, as well as in selected categories within variables, are presented in Table 2. The overall value of 0.183 was very similar to the 0.170 value estimated by Carvajal, Armayor'. Earnings inequality increased with age and with years of professional experience reported by pharmacists, and it was greater for part-time than full-time pharmacists and for pharmacists without a PharmD degree than for those who held a PharmD degree. The Gini coefficient values were very similar for married pharmacists and for pharmacists who were not married. In terms of main professional role, inequality was greater for pharmacists dispensing medications and reporting other activities than for clinical pharmacists; in terms of primary practice site, pharmacists in retail and other settings exhibited greater inequality in wages and salaries than hospital pharmacists.

Overall wages and salaries were more evenly distributed for female than male pharmacists, although the dispersion pattern was disjointed for both genders in virtually every variable. Taking into consideration differences in the Gini coefficient values of at least $25 \%$, the empirical evidence showed more inequality within younger women than younger men but within older men than older women, within full-time male than female pharmacists but within part-time female than male pharmacists, within female than male practitioners with less professional experience but within male than female practitioners with more experience, within female than male clinical pharmacists but within male than female pharmacists whose primary role was other (e.g., neither clinical nor dispensing), and within male than female pharmacists in retail and other practice settings but within female than male hospital pharmacists. In addition, the levels of inequality were about the same for both genders of married practitioners but greater for female than male practitioners who were not married and similar for both genders of pharmacists with a PharmD degree but greater for male than female practitioners who did not have a PharmD degree.

\section{DISCUSSION}

Several findings may be highlighted from this probe into the central tendency and dispersion of U.S. pharmacists' wages and salaries. The first is that when all observations in the data set were analyzed, the wages and salaries of male pharmacists exceeded those of female pharmacists. A closer look at the data, however, revealed that the earnings gender gap was present mainly in selected categories of practitioners-older, married, with more years of experience, and whose primary role was dispensing medications in a hospital setting. Most of these variables tend to be intuitively correlated with one another; generally, older pharmacists are married and have the capacity of accumulating more years of experience, many of them dispensing medications, which is one of the traditional and most common roles of the profession. Furthermore, the empirical evidence indicated that practitioners dispensing medications and/or working in retail and hospitals earned lower wages and salaries than their counterparts. These patterns raise an interesting question: As younger practitioners become older and pharmacists' roles continue to diversify, will the overall earnings gap narrow and eventually disappear if the conditions for their existence fade away or will the gap remain, perhaps fueled by new sources of disparity between the genders?

Second, although the data seemingly supported the contention by Goldin, Katz ${ }^{1}$ that pharmacy is indeed an egalitarian profession, pockets of inequality became evident in the distribution of wages and salaries. When the observations for both men and women were merged, older pharmacists, with more years of professional experience and whose primary role was dispensing medications, exhibited more inequality within their distribution than the rest of the practitioners, a generalization that accords with earlier findings by Carvajal, Armayor $^{9}$. It is worth noting that these were some of the groups that showed higher earnings levels for male than female pharmacists.

A more thorough probe into the separate data sets for both genders revealed greater inequality in the distribution of wages and salaries of male than female pharmacists, which also supports the findings by Carvajal, Armayor ${ }^{9}$. Far from being similar, as suggested by Goldin, Katz ${ }^{1}$, the earnings spread patterns for male and female practitioners were heterogeneous, and different gender-specific pockets of inequality became apparent in all variables and virtually all categories within variables. Male pharmacists who were 55 years and older, worked full time, had at least 30 years of professional experience, did not have a PharmD degree, whose main role at work was neither clinical nor dispensing, and whose primary practice site was retail or "other" exhibited a more uneven distribution of wages and salaries than their female counterparts in those categories. Some older men in this group, approaching retirement age, might have opted to work fewer hours, while still working full time, thus increasing the spread in the distribution of wages and salaries. Moreover, 
the dissimilarity of roles within the "other" practice site category might have contributed to the broader spread of this group.

By the same token, female pharmacists who were younger than 55 years of age, worked under 35 hours per week, had less than 30 years of experience, were not married, whose main role at work was clinical, and worked in hospitals showed a more uneven distribution of wages and salaries than their male counterparts. Women, especially younger women, are more likely than men to work part time ${ }^{2}$, and the greater spread in the number of hours worked might be responsible for the observed greater dispersion in the wages and salaries of this group. Thus, the apparently smooth gender-specific distribution of earnings in the pharmacy profession portrayed by Goldin, Katz ${ }^{1}$ might be the result of opposing trends by different groups of practitioners that cancel each other when analyzed aggregately. This was the main finding of the article.

\section{Limitations}

The interpretation of the findings reported here is subject to several limitations. Self-reported data were used; by their nature, they are the target of validity and reliability criticism, even though in this study the questionnaire was tested prior to being mailed to participants. No incentives such as monetary compensation or raffle prizes were used to motivate survey participation, which might have altered both the number of respondents and the nature of the responses. Ultimately, there was no way to corroborate that the questionnaires were received or filled by the intended respondents, which was crucial to the validity issue. Furthermore, although the MMS data files were broad-based and included approximately $90 \%$ of pharmacists practicing in 2012, not all pharmacists belonged to an organization; therefore, the data file might not have been representative of a small portion of the pharmacist workforce. The modest response rate obtained, which might be perceived by some analysts as a limitation, was compensated by the fact that the sample consisted of 654 observations, which was a sizable data file.

Another limitation was that the empirical work rested on crosssectional data. Neither changing tastes and preferences nor institutional constraints, such as the implementation and partial abrogation of the Affordable Care Act, were considered in the model. Reported levels of wage-and-salary earnings were not adjusted for differences in the cost of living or tax structures throughout the nation, which might have introduced an upward bias into the estimated Gini coefficient values; practitioners working or living in areas characterized by higher cost-of-living indices and/or more taxes tend to be paid higher money wages and salaries for comparable work in order to maintain similar real income levels, thus inflating observed inequalities in the distribution of earnings. Furthermore, crosssectional data are inadequate to identify patterns of earnings growth and distribution over time, so the effects of recent changes in the pharmacist workforce profile brought about by fewer new independent pharmacies, a lower pharmacists' retirement rate than previously anticipated, and an increase in the annual number of graduating pharmacists likely went undetected.

Still another limitation was the choice of indicator used to measure the dispersion of wages and salaries. Although the Gini coefficient is widely used, it does not differentiate among kinds of disparity. Heterogeneous patterns of wage-and-salary distributions, depicted by intersecting Lorenz curves, may yield identical Gini coefficient values as long as the total areas above and below the curve remain the same. Moreover, the Gini coefficient is more sensitive to wage-and-salary changes in the middle than at the extremes of the distribution; its value is affected more by an earnings transfer from one pharmacist to another in the middle than at either end of the wage-and-salary spectrum.

\section{CONCLUSION}

Despite these limitations, the article has successfully estimated both the central tendency and dispersion of wages and salaries for selected categories of pharmacists, compared the earnings levels of male and female practitioners, and examined the pockets of inequality that exist within each gender. Insofar as the approach is novel, findings should be regarded as preliminary in nature; bringing into the analysis new variables and functional relationships should be a deliberative process subject to empirical verification. While the methodological focus here on univariate rather than multivariate analysis has been conducive to the identification of pockets of inequality, it does not allow the exploration of how the other variables affect pharmacists' wages and salaries. This would be an excellent topic for further research. In any event, the study has shed light into the earnings structure within pharmacy and hopefully will act as a catalyst for subsequent insights into the dynamics of the pharmacist workforce.

\section{Conflicts of interest: none.}

Funding: This research was supported solely by internal university funds. It did not receive any specific grant from funding agencies in the public, commercial, or not-for-profit sectors. 


\section{References}

1. Goldin C, Katz LF. The most egalitarian of all professions: Pharmacy and the evolution of a familyfriendly occupation. National Bureau of Economic Research; 2012.

2. Carvajal MJ, Armayor GM, Deziel L. The gender earnings gap among pharmacists. Res Social Adm Pharm. 2012;8(4):285-297.

3. Kim C, Sakamoto A. The rise of intra-occupational wage inequality in the United States, 1983 to 2002. Am Sociol Rev. 2008;73(1):129-157.

4. Dobre MH, Ailenei D, Mosora LC. Analysis of gender discrimination using the Gini index multiple decomposition method. African Journal of Business Management. 2013;7(26):2576-2582.

5. Haag A, Schockmel M. Are Women Discriminated on the Labour Market in Luxembourg? 2007; https://www.researchgate.net/publication/26650108 7_Are_Women_Discriminated_on_the_Labour_Mark et_in_Luxembourg.

6. Chibba M. Inequality, The Gini Index, Gender Bias and Other Related Issues. Interdisciplinary Perspectives on Equality and Diversity. 2016;2(1).

7. Dorius SF, Firebaugh $\mathrm{G}$. Trends in global gender inequality. Soc Forces. 2010;88(5):1941-1968.

8. Larraz B. Decomposing the Gini inequality index: An expanded solution with survey data applied to analyze gender income inequality. Sociological Methods \& Research. 2015;44(3):508-533.

9. Carvajal MJ, Armayor GM. Inequalities in the distribution of pharmacists' wage-and-salary earnings: Indicators and their development. Res Social Adm Pharm. 2013;9(6):930-948.

10. Carvajal MJ, Armayor GM. The life-cycle argument: Age as a mediator of pharmacists' earnings. Res Social Adm Pharm. 2015;11(1):129-133.

11. Carvajal MJ, Popovici I. Pharmacists' wages and salaries: The part-time versus full-time dichotomy. Res Social Adm Pharm. 2016;12(2):341-346.

12. Carvajal MJ, Armayor GM, Deziel L. Pharmacists' earnings determinants: Differences by ethnic group. J Pharm Health Serv Res. 2013;4(1):19-27.

13. Campano F, Salvatore D. Income Distribution: Includes CD. Oxford University Press; 2006.

14. De Maio FG. Income inequality measures. J Epidemiol Community Health. 2007;61(10):849-852.

15. Shkolnikov VM, Andreev EE, Begun AZ. Gini coefficient as a life table function: Computation from discrete data, decomposition of differences, and empirical examples. Demographic Res. 2003;8:305358.
16. Alvaredo F. A note on the relationship between top income shares and the Gini coefficient. Econ Lett. 2011;110(3):274-277.

17. Chen C-N, Tsaur T-W, Rhai T-S. The Gini coefficient and negative income. Oxf Econ Pap. 1982;34(3):473478.

18. Chotikapanich D, Griffiths WE. Estimating Lorenz curves using a Dirichlet distribution. J Bus Econ Stat. 2002;20(2):290-295.

19. Cowell F. Measuring inequality. Oxford University Press; 2011.

20. Gastwirth JL. The estimation of the Lorenz curve and Gini index. REStat. 1972;54(3):306-316.

21. Milanovic B. A simple way to calculate the Gini coefficient, and some implications. Econ Lett. 1997;56(1):45-49.

22. Manso EP. The influence of earnings on income distribution in the United States. J Socio Econ. 2006;35(4):710-726.

23. Moskowitz CS, Seshan VE, Riedel ER, Begg CB. Estimating the empirical Lorenz curve and Gini coefficient in the presence of error with nested data. Stat Med. 2008;27(16):3191-3208.

24. Bureau of Labor Statistics. Occupational Employment and Wages: Pharmacists 2014: 29-1051. 2014; http://www.bls.gov/oes/2014/may/oes291051.htm. Accessed October 18, 2017.

25. Carvajal MJ, Popovici I, Hardigan PC. Gender differences in the measurement of pharmacists' job satisfaction. Hum Resour Health. 2018;16(1):33.

26. Carvajal MJ, Popovici I, Hardigan PC. Pharmacists' earnings determination: Are part-time practitioners homogeneous in their response? J Pharm Health Serv Res. 2017;8(1):13-21.

27. Cochran WG. Sampling techniques. 2nd ed: John Wiley \& Sons; 1963.

28. Lin BY-J, Yeh Y-C, Lin W-H. The influence of job characteristics on job outcomes of pharmacists in hospital, clinic, and community pharmacies. J Med Syst. 2007;31(3):224-229.

29. Murphy SM, Friesner DL, Scott DM. Do in-kind benefits influence pharmacists' labor supply decisions? Journal of Regional Analysis \& Policy. 2011;41(1):33-52.

30. Polgreen LA, Mott DA, Doucette WR. An examination of pharmacists' labor supply and wages. Res Social Adm Pharm. 2011;7(4):406-414.

31. Quiñones AC, Pullin RF. Reexamining shift work pharmacists in Illinois. Res Social Adm Pharm. 2011;7(4):444-450. 
Table 1. Estimated means and standard deviations (in parentheses) of male and female pharmacists' annual wages and salaries by selected variables and categories within variables.

\begin{tabular}{|c|c|c|c|c|c|c|c|}
\hline \multirow{3}{*}{ Category } & \multicolumn{6}{|c|}{$\begin{array}{l}\text { Means and Standard Deviations } \\
\text { (dollars) }\end{array}$} & \multirow{3}{*}{$\begin{array}{c}\text { Male- } \\
\text { Female } \\
\text { Pharmacist } \\
\text { Ratio }\end{array}$} \\
\hline & \multicolumn{2}{|c|}{ Both Genders } & \multicolumn{2}{|c|}{ Male Pharmacists } & \multicolumn{2}{|c|}{$\begin{array}{l}\text { Female } \\
\text { Pharmacists }\end{array}$} & \\
\hline & \# & $\begin{array}{l}\text { Wages } \\
\text { and } \\
\text { Salaries }\end{array}$ & \# & $\begin{array}{l}\text { Wages and } \\
\text { Salaries }\end{array}$ & \# & $\begin{array}{l}\text { Wages and } \\
\text { Salaries }\end{array}$ & \\
\hline All categories & 654 & $\begin{array}{l}110,581.3 \\
(50,077.1)\end{array}$ & 375 & $\begin{array}{l}114,241.0^{\ddagger} \\
(60,326.4)\end{array}$ & 279 & $\begin{array}{l}105,662.3^{\ddagger} \\
(30,855.7)\end{array}$ & 1.08 \\
\hline Age: Less than 40 years old & 101 & $\begin{array}{l}113,282.1 \\
(26,051.0)\end{array}$ & 38 & $\begin{array}{l}116,478.9 \\
(17,367.3)\end{array}$ & 63 & $\begin{array}{l}111,353.8 \\
(30,075.9)\end{array}$ & 1.05 \\
\hline Age: $40-54$ years old & 243 & $\begin{array}{l}111,129.3 \\
(33,266.3)\end{array}$ & 109 & $\begin{array}{l}118,132.2^{*} \\
(32,507.4)\end{array}$ & 134 & $\begin{array}{l}105,433.0^{*} \\
(32,903.1)\end{array}$ & 1.12 \\
\hline Age: 55 years and older & 310 & $\begin{array}{l}109,271.8 \\
(64,875.4)\end{array}$ & 228 & $\begin{array}{l}112,007.8^{+} \\
(73,695.0)\end{array}$ & 82 & $\begin{array}{l}101,664.4^{+} \\
(27,498.1)\end{array}$ & 1.10 \\
\hline $\begin{array}{l}\text { Worked at least } 35 \text { hours per week } \\
\text { (full time) }\end{array}$ & 510 & $\begin{array}{l}121,320.4^{\mathrm{a}} \\
(43,888.3)\end{array}$ & 310 & $\begin{array}{l}123,039.5 \\
(53,600.6)\end{array}$ & 200 & $\begin{array}{l}118,656.0 \\
(21,305.1)\end{array}$ & 1.04 \\
\hline $\begin{array}{l}\text { Worked less than } 35 \text { hours per week } \\
\text { (part time) }\end{array}$ & 144 & $\begin{array}{l}72,546.8^{a} \\
(52,222.0)\end{array}$ & 65 & $\begin{array}{c}72,279.1 \\
(72,335.6)\end{array}$ & 79 & $\begin{array}{c}72,767.1 \\
(26,577.7)\end{array}$ & 0.99 \\
\hline Experience: Under 15 years & 102 & $\begin{array}{l}109,847.1 \\
(27,576.4)\end{array}$ & 46 & $\begin{array}{l}112,852.2 \\
(24,607.1)\end{array}$ & 56 & $\begin{array}{l}107,378.7 \\
(29,787.6)\end{array}$ & 1.05 \\
\hline Experience: $15-29$ years & 241 & $\begin{array}{l}112,830.1 \\
(32,411.7)\end{array}$ & 98 & $\begin{array}{l}122,380.1^{*} \\
(30,534.4)\end{array}$ & 143 & $\begin{array}{l}106,285.3^{*} \\
(32,133.5)\end{array}$ & 1.15 \\
\hline Experience: 30 years and more & 311 & $\begin{array}{l}109,079.5 \\
(64,922.6)\end{array}$ & 231 & $\begin{array}{l}111,064.7 \\
(73,262.3)\end{array}$ & 80 & $\begin{array}{l}103,347.3 \\
(29,468.2)\end{array}$ & 1.07 \\
\hline Marital status: Married & 506 & $\begin{array}{l}111,655.8 \\
(53,932.2)\end{array}$ & 306 & $\begin{array}{c}116,835.9^{*} \\
(63,688.5)\end{array}$ & 200 & $\begin{array}{l}103,730.1^{*} \\
(32,559.3)\end{array}$ & 1.13 \\
\hline Marital status: Not married & 148 & $\begin{array}{l}106,907.8 \\
(33,611.9)\end{array}$ & 69 & $\begin{array}{l}102,733.1 \\
(40,718.5)\end{array}$ & 79 & $\begin{array}{l}110,554.0 \\
(25,590.0)\end{array}$ & 0.93 \\
\hline
\end{tabular}




\begin{tabular}{|c|c|c|c|c|c|c|c|}
\hline PharmD degree: Yes & 161 & $\begin{array}{l}118,975.2^{b} \\
(26,782.0)\end{array}$ & 72 & $\begin{array}{c}125,483.9^{*} \\
(26,646.4)\end{array}$ & 89 & $\begin{array}{l}113,709.8^{*} \\
(25,856.7)\end{array}$ & 1.21 \\
\hline PharmD degree: No & 493 & $\begin{array}{l}107,840.1^{b} \\
(55,357.8)\end{array}$ & 303 & $\begin{array}{l}111,569.4^{\ddagger} \\
(65,594.9)\end{array}$ & 190 & $\begin{array}{l}101,892.7^{\ddagger} \\
(32,316.1)\end{array}$ & 1.09 \\
\hline Main role: Clinical & 72 & $\begin{array}{l}115,618.5^{\mathrm{c}} \\
(28,237.2)\end{array}$ & 43 & $\begin{array}{l}114,417.1 \\
(32,152.4)\end{array}$ & 29 & $\begin{array}{l}117,400.0 \\
(21,579.0)\end{array}$ & 0.97 \\
\hline Main role: Dispensing & 458 & $\begin{array}{l}106,694.9^{c} \\
(52,452.1)\end{array}$ & 269 & $\begin{array}{l}110,767.4^{\ddagger} \\
(62,392.5)\end{array}$ & 189 & $\begin{array}{l}100,898.7^{\ddagger} \\
(32,878.2)\end{array}$ & 1.10 \\
\hline Main role: Other & 124 & $\begin{array}{l}122,010.9^{c} \\
(49,277.3)\end{array}$ & 63 & $\begin{array}{l}128,952.5 \\
(64,447.2)\end{array}$ & 61 & $\begin{array}{l}114,841.7 \\
(24,149.1)\end{array}$ & 1.12 \\
\hline Practice setting: Retail & 408 & $\begin{array}{l}106,500.8^{d} \\
(42,383.3)\end{array}$ & 233 & $\begin{array}{l}108,704.9 \\
(48,749.3)\end{array}$ & 175 & $\begin{array}{l}103,566.3 \\
(31,905.8)\end{array}$ & 1.05 \\
\hline Practice setting: Hospital & 148 & $\begin{array}{l}110,947.6^{d} \\
(29,647.7)\end{array}$ & 84 & $\begin{array}{l}116,375.0^{\ddagger} \\
(27,649.7)\end{array}$ & 64 & $\begin{array}{l}103,824.1^{\ddagger} \\
(30,869.6)\end{array}$ & 1.12 \\
\hline Practice setting: Other & 98 & $\begin{array}{l}127,016.2^{d} \\
(87,575.2)\end{array}$ & 58 & $\begin{array}{c}133,390.3 \\
(112,194.9)\end{array}$ & 40 & $\begin{array}{l}117,773.6 \\
(23,016.8)\end{array}$ & 1.13 \\
\hline
\end{tabular}

'Male pharmacists' earnings significantly greater than female pharmacists' earnings ( $p \leq 0.01)$.

${ }^{\ddagger}$ Male pharmacists' earnings significantly greater than female pharmacists' earnings ( $\left.p \leq 0.05\right)$.

'Male pharmacists' earnings significantly greater than female pharmacists' earnings $(p \leq 0.10)$.

${ }^{a}$ Full-time significantly greater than part-time $(p \leq 0.01)$.

${ }^{b}$ PharmD degree significantly greater than no PharmD degree $(p \leq 0.01)$.

'Dispensing significantly lower than clinical $(p \leq 0.05)$ and other $(p \leq 0.01)$, but clinical and other not significantly different from each other.

${ }^{d}$ Other significantly greater than retail $(p \leq 0.05)$ and hospital $(p \leq 0.10)$, but retail and hospital not significantly different from each other. 
Table 2. Estimated Gini coefficient values of male and female pharmacists' annual wages and salaries by selected variables and categories within variables.

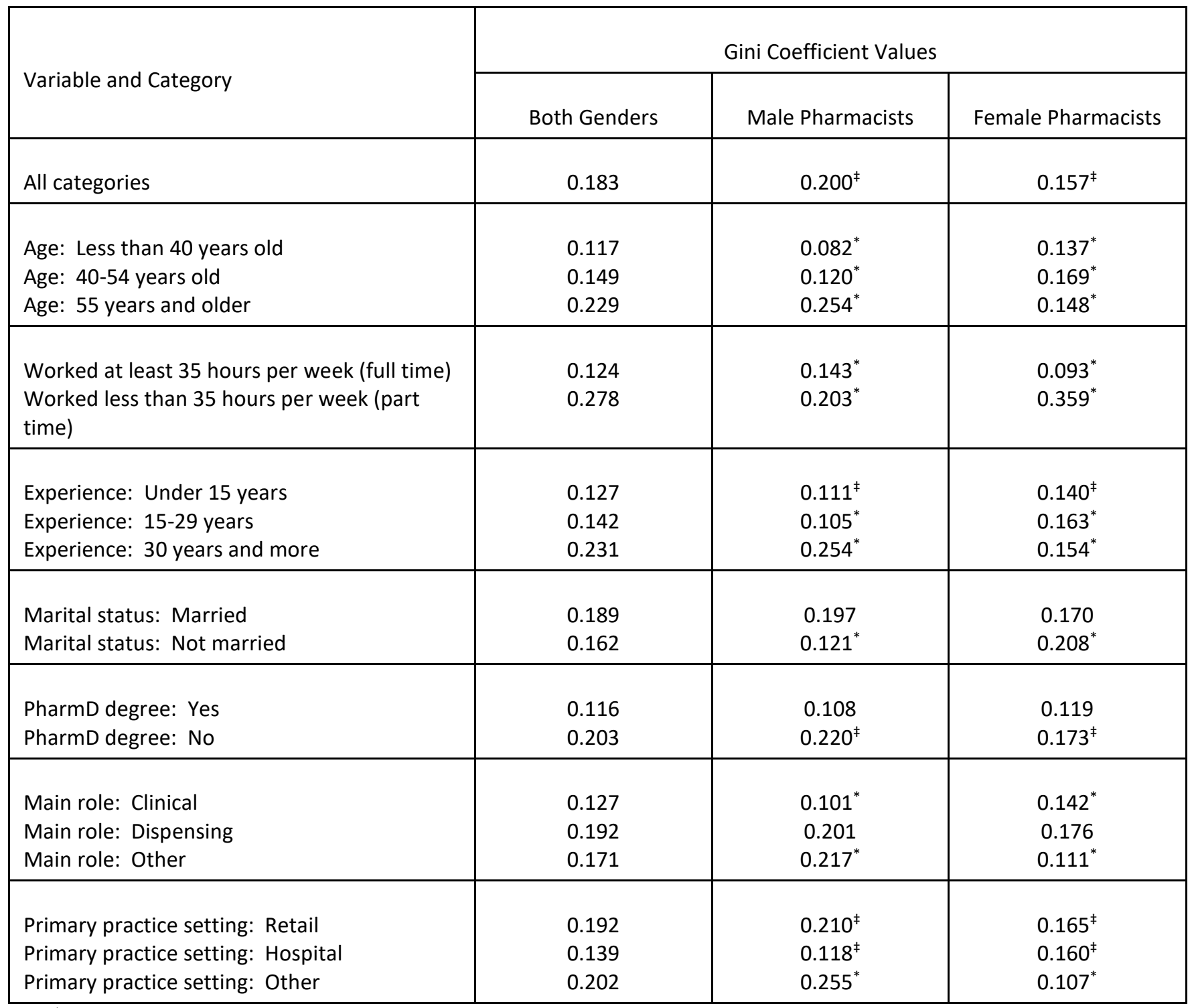

${ }^{*}$ At least a $40 \%$ difference exists between the values of male and female pharmacists.

${ }^{\ddagger}$ At least a $25 \%$ difference exists between the values of male and female pharmacists. 
Figure 1. Illustration of a hypothetical Lorenz curve.

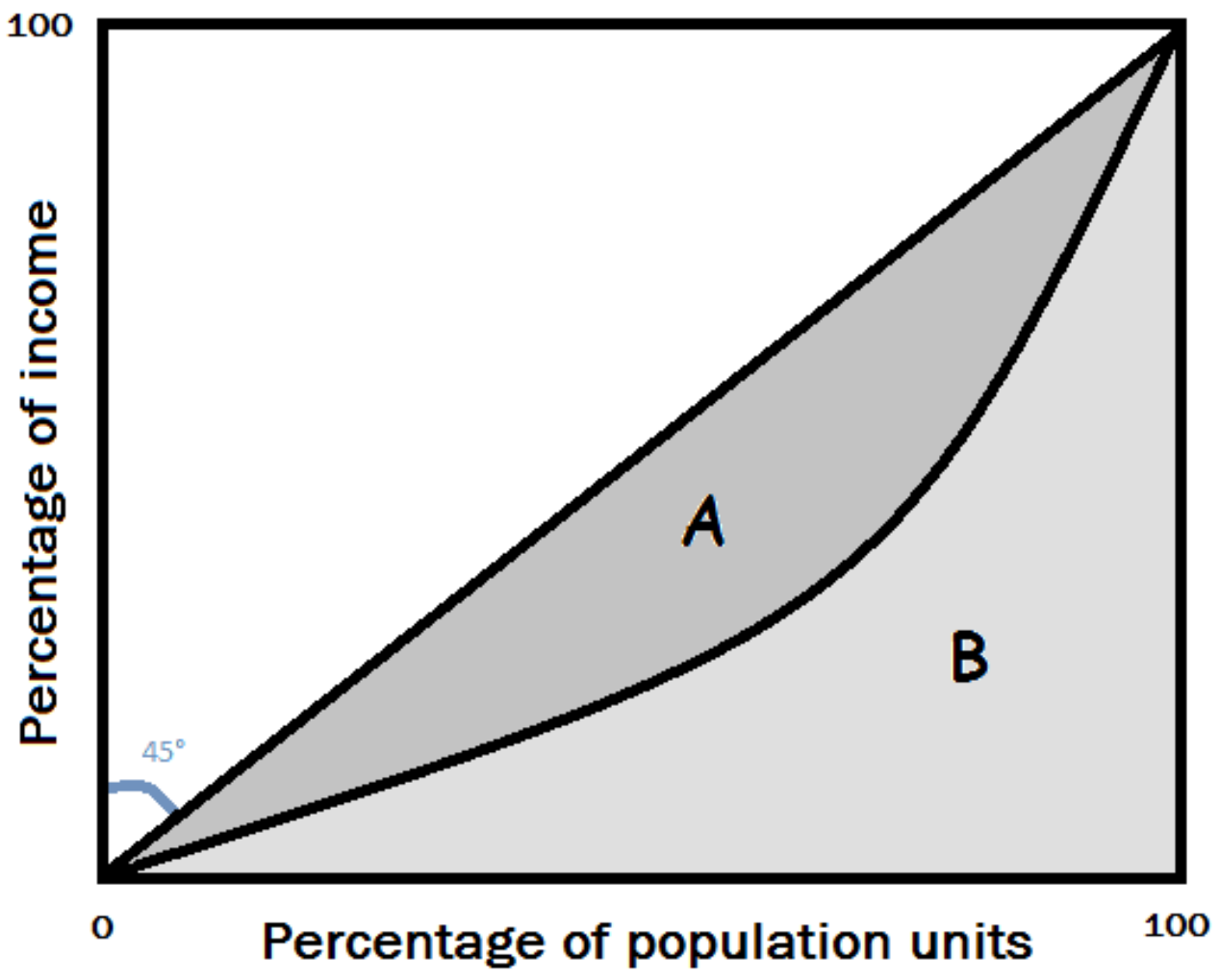

